\title{
POLA KONSUMSI DALAM ISLAM DAN KONSEP ECO-SUFISME MUHAMMAD ZUHRI
}

\author{
Suwito NS \\ STAIN Purwokerto \\ Jl. A. Yani 40-A, (+62-281) 635624, Purwokerto 53126 \\ E-mail: suwitons@gmail.com \\ HP. +62-8122739120
}

Abstract: This article explores a new view of the relationship between the consumption patterns and spiritual transformation, which is discussed in a Sufi perspective. Hunger tradition as Sufi's consumption pattern is seen by Muhammad Zuhri as a medium for self-recognition. If someone has been able to get to know himself, then it will gradually know the quality of himself. Humans, is individually a weak creature, can not live without the help of another man and the universe. In this context, the cosmos and the self is "Theophany" of God. Humans are as caliph who serve the Lord and at the same time taking care of the universe. Fasting in religions teach this consciousness. Fasting as one of the Sufi tradition have multi function, namely as a means for someone to be close to God, man, and the universe.

Abstrak: Artikel ini mencoba mengeksplorasi sebuah pandangan baru kaitan antara pola konsumsi dengan transformasi ruhani. Tulisan ini menawarkan solusi baru atas kerusakan lingkungan dalam perspektif Sufi. Tradisi lapar -yang merupakan pola konsumsi dalam Sufi- menurut Muhammad Zuhri dipandang sebagai media untuk pengenalan diri (self recognition). Jika seseorang telah dapat mengenal diri, maka secara bertahap akan mengetahui kualitas diri. Manusia, secara individual adalah diri yang lemah. Diri ini tidak bisa hidup tanpa bantuan aspek lain, yaitu manusia lain dan alam semesta. Berangkat dari pengenalan akan kesadaran diri ini kemudian bertransfomasi pada kesadaran kosmis. Alam harus dirawat dijaga dan dilestarikan. Dalam konteks ini kosmos dan diri adalah "teofani" Tuhan. Manusia adalah sebagai khalifah yang mengabdi pada Tuhan dan sekaligus merawat alam semesta. Puasa dalam agama-agama mengajari kesadaran ini. Puasa sebagai salah satu tradisi Sufi memiliki fungsi multi, yakni sebagai cara agar seseorang dapat dekat dengan Tuhan, manusia, dan alam semesta.

Kata Kunci: reducing consumption, konsumsi, Sufi, teofani, nafsu. 


\section{A. Pendahuluan}

Konsumsi yang berlebihan (excessive consumption) dan pertumbuhan jumlah penduduk yang pesat (over population) adalah dua hal yang menjadi problem global dewasa ini. Dua hal tersebut saling terkait antara satu dengan yang lainnya. Jumlah penduduk yang semakin meningkat tajam di dunia akan mempengaruhi kebutuhan konsumsi (Kolandai, 1999: 1-50).

Faktor konsumsi yang berlebihan akan membawa daftar panjang persoalan manusia dewasa ini, meliputi masalah, 1) sosial, 2) lingkungan, 3) moral, dan 4) spiritual. Sementara itu, over populasi akan menyebabkan berbagai persoalan seperti 1) penyakit, 2) instabilitas politik, 3) diskriminasi, dan 4) pertumbuhan kebutuhan akan konsumsi.

Dalam konteks kehidupan sosial, konsumsi suatu masyarakat dipengaruhi oleh gaya hidup, yang ini seringkali melahirkan problem sosial di antaranya adalah kesenjangan dan diskriminasi sosial, bahkan, juga problem etika. Rayan (1990: 19) mengidentifikasi problem etika terkait dengan pola konsumsi, di antara adalah ketamakan (greed), pola hidup komsumerisme (comsumerism), dan persaingan tidak sehat (negative competition). Problem etik ini menyebabkan dehumanisasi, yang seringkali memperparah kerusakan lingkungan. Dengan demikian, problem etika ini selanjutnya akan menyebabkan lenyapnya kehidupan, mulai dari keragaman hayati, pemanasan global, dan pencemaran (air, udara) (Durning: 1994: 43).

Tulisan ini akan membahas masalah pola konsumsi yang secara normatif telah diatur oleh agama-agama. Islam sebagai sebuah agama memberikan kontribusi normatif mengatasi masalah ini. Dogma-dogma Islam kemudian dipahami oleh pemeluknya dalam berbagai disiplin ilmu. Islam dalam tulisan ini dispesifikkan (diciutkan) pada disiplin Sufisme, dengan kasus pemikiran tentang kesederhanaan melalui jalan lapar dan etika lingkungan menurut Muhammad Zuhri sebagai pintu masuk kajian.

\section{B. Eco-sufisme: Sebuah Konstruk}

Kata eco-sufism, sebagaimana kajian Suwito NS (2011: 18-30), konsep ini pernah disebut di kalangan penganut Universal Sufism atau sering disebut The Sufi Order in the West, sebuah cabang Sufi yang didirikan oleh Hazrat Inayat Khan (1882-1927).

Paling tidak ada tiga pemahaman tentang Sufi, yakni Sufi sebagai 1) sistem etika/moral, 2) seni/estetika, 3) atribut.

Ibn Khafif sebagaimana Baldick (1998: 230) mengatakan bahwa hakikat Sufi adalah "penampakan diri". Sifat-sifat sufi diejawantahkan pada perbuatan. 
Perbuat an lahir sebagai penanda (atribut/identitas). Dengan kata lain, sufi adalah aspek batiniyah kepribadian (etika) yang terungkap dan memancar terang (atribut).

Dalam konteks ini, ahl al-suffah, yang dirujuk sebagai asal muasal lahirnya istilah sufi, dilihat sebagai fakta adanya "atribut" atau identitas sosial. Kelompok ini memiliki karakter sosial yang khas. Kesederhanaan, kepatuhan, orientasi ketuhanan, kerarifan, dan kesetiakawanan adalah karakter yang menonjol dari ahl al-suffah ini. Atribut ini menjadi "identitas khas bersama" mereka yang berbeda dengan atribut kelompok lain. Aspek sufi sebagai atribut juga dikatakan oleh Suryadi (2001: 57-124).

Kajian-kajian tentang Sufisme dan gerakan sosial sebagaimana dilakukan oleh Ernst (1997), Sirriyeh (1999), Kartodirdjo (1966, 1970), Djamil (2001). Sementara itu, Machasin (2004) lebih melihat fenomena lahirnya pasar (aktivitas ekonomi) pada persaudaraan sufi dalam tarekat.

Eco-sufisme atau green Sufisme adalah konsep baru Sufi yang dikonstruk melalui penyatuan kesadaran antara kesadaran berlingkungan dan berketuhanan, yakni, 1) kesadaran berlingkungan (save it, study it, and use it) adalah bagian tidak terpisahkan dari kesadaran spiritual (spiritual consciousness). Menyintai alam semesta merupakan bagian dari menyintai Tuhan. Menyintai sesuatu yang menjadi milik Tuhan sama merupakan bagian dari menyintai Tuhan, 2) mengupayakan adanya proses transformasi dari spiritual consciousness menuju ecological consciousness (tataran implementasi/gerakan). Tujuannya adalah keserasian semesta (harmony in natura) dan keserasian (kesesuaian, taufiq) antara pelaku sufi dengan Tuhan. Kondisi ini yang kemudian membuahkan cinta timbal balik (antara manusia dengan Tuhan, manusia dengan manusia, dan manusia dengan alam semesta).

Dengan demikian, etika eco-sufism mendorong perilakunya hidup selaras dengan Allah dan alam (harmoni in nature). Sistem etika ini kemudian melahirkan keindahan (estetika). Kedua aspek ini (sistem etika dan estetika) kemudian menjadi atribut diri dan sosial sehingga eco-sufism memiliki corak tersendiri (berbeda) dengan Sufi lain (Suwito NS, 2011: 20-25).

\section{Pola Konsumsi dan Transformasi Spiritual}

Istilah konsumsi dipahami sebagai aktivitas menggunakan, menghabiskan, atau memanfaatkan barang atau jasa untuk mememuhi kebutuhan hidup. Ada barang yang langsung habis, ada yang berangsur habis. Tujuan konsumsi dibedakan menjadi 1) konsumsi sosial, 2) produktif, 3) keindahan, 4) masa depan, 5) keamanan dan kesehatan, 6) kesenangan/hobi/kepuasan. 
Dalam agama Hindu, berlebihan dalam berkonsumsi dipandang negatif. Temuan Kolandai menurut ajaran Hindu, "If you have more that you need, then you are stealing, you are a thief!" Pola konsumsi dalam pandangan Hindu didasarkan pada keyakinan bahwa seseorang memiliki kuota (jatah) tertentu yang diberikan Tuhan, jika melebihi batas jatah ini maka dia akan menyengsarakan diri dan orang lain (Kolandai, 1994: 22) "Is based on the belief that everyone has a certain quota given by God and that when one exceeds this quota it leads to the suffering of oneself, and of others. Singkatnya, jika seseorang makan terlalu banyak, maka ia mengonsumsi porsi orang lain. Di samping itu, terlalu banyak mengonsumsi akan lebih cepat menipiskan sumber daya alam. Sumber daya alam yang menipis dan terbatas akan mengakibatkan krisis. Dengan demikian, kemurahan hati, kesederhanaan hidup, kehidupan spiritual, daur ulang, menghindari konsumsi yang tidak mendesak adalah prinsip-prinsip dalam Hinduisme. Prinsip kesederhanaan untuk membantu orang lain dapat digunakan untuk mengatasi masalah konsumsi dan konsumerisme. Masih dalam konsumsi, Hindu juga dianjurkan untuk vegetarianisme.

Di samping itu, tradisi Hindu berkeyakinan bahwa bumi adalah suci dan bahkan sebagai Tuhan (as the body of God Himself). Mahatma Gandi menekankan hidup sederhana (Renard, 1999: 149). Adapun Coward mengatakan bahwa ajaran Hindu mengutuk dan menghukum penebangan tumbuhan dan perburuan yang bertujuan untuk memenuhi ketamakan manusia (Coward: 1993: 50-52).

Teori Karma (Horner, 1959: 283) dan dalam Hindu juga mengatakan bahwa seluruh alam semesta saling berhubungan, dunia materi dapat digunakan untuk meningkatkan kualitas hidup bahkan dapat digunakan untuk berhubungan dengan Tuhan.

Agama Buddha secara tegas tidak menoleransi konsumsi berlebihan yang merupakan bukti kehampaan spiritualitas (Hayden, 1996: 170-171). Budaya belanja (shopping culture) pada masyarakat bukan jawaban untuk mendapatkan kebahagiaan. Budaya shopping bertentangan dengan konsep samsara.

Menurut Dalai Lama \& Carriere (1994: 83), Buddha meyakini bahwa sumber daya alam yang ada di bumi adalah terbatas. Walau demikian, manusia telah lupa tujuan hidup yang sebenarnya. Manusia tumbuh menjadi makhluk yang materialistik dengan mereka didorong oleh ketamakan dan kerakusan. Padahal seseorang memiliki ketercukupan basis spiritual. Pendapat Dalai Lama \& Carriere memperkuat Ikeda (1976: 81-84), yang mengatakan bahwa kemakmuran masyarakat sekarang hanya diukur dengan aspek material. Padahal masih ada ukuran lain yakni keramahan dan humanity. 
Buddha menawarkan banyak term yang dipandang sebagai tawaran spiritual untuk mengurangi konsumsi. Sebagaimana dikatakan Kolandai (1999: 23) sebagai Hayden (1996: 170-171) bahwa tujuan hidup menurut Buddha adalah "to detach one's self from craving material things, permanence, or immortality. Buddha juga mengajarkan kesederhanaan hidup dan tidak membolehkan sikap berlebih-lebihan dalam konsumsi.

Sementara dalam tradisi Kristen, krisis lingkungan (environmental crisis) seringkali dikaitkan dengan pendekatan ekspoitatif terhadap alam JudeoChristiani yang didasarkan pada tafsir Genesis 1: 282, yang mana manusia memiliki sifat dominan terhadap alam. White (1967: 203) menuduh JudeoKristiani sebagai biang kerusakan lingkungan. Hal ini sebagaimana dikatakan White, "Christianity... insisted that it is God's will that man exploit nature for his proper ends" (White, 1967: 1205). Hal ini senada dengan pernyataan Toynbee (1972: 141-146) yang juga menyalahkan gereja. Menurutnya, gereja sepat utnya bertanggung jawab at as "the present environmental crisis," karena telah memberikan legitimasi eksploitasi atas alam (Lihat Woodrum and Davison, 1996: 77). Baik White maupun Toynbee menyarankan reinterpretasi Bible yang lebih ramah terhadap lingkungan.

Interpretasi baru dilakukan oleh Rayan (1999), Pope John Paul II, Harrison (1999: 81-88) yang mencoba melakukan interpretasi ulang terhadap Genesis 1:282 yang pemahamannya berbeda dengan pemahaman lama. Bagi Rayan, kata "to dominate" dalam Genesis dipahami dengan "to serve" yang dalam makna selanjutnya berarti "cultivate it", (mengolah, bersahabat) and maintain its fruitfulness and beauty, to ensure a joyous home for all generations (Harrison, 1999: 86-88).

Pope John Paul II mengatakan bahwa terdapat hubungan langsung antara pola hidup konsumerisme dengan problem lingkungan. Pesan ini disampaikan pada World Day of Peace on $1^{\text {st }}$ January 1990, baginya, “The environmental crisis is the direct result of sin, greed and the contemporary tendency to seek for immediate gratification through consumerism" (Northcott, 1996: 37).

Dari beberapa rujukan kitab suci yang diusung Kristiani, mengatakan bahwa konsumsi yang berlebihan (excessive consumption) adalah pertanda dari ketiadaan spiritualitas (lack of spirituality). Perilaku orang yang memiliki tingkat spiritualitas yang tinggi adalah dengan cara mengurangi konsumsi (menghemat resources) dan mendistribusikannya dengan lebih baik. Hal ini karena pemahaman bahwa sumber daya alam adalah terbatas.

Salah satu cara untuk mengurangi konsumsi adalah dengan pendekatan spiritual. Di antara sikap pro lingkungan adalah dengan daur ulang (recycling), 
reusing, membeli produk pro lingkungan, membatasi konsumsi (limiting one's comsumtion atau reduce consumtion), simple lifestyle (dengan belajar merasa senang walau memiliki sedikit).

Sementara itu, dalam Islam, secara tegas al-Quran melarang umatnya berlebih-lebihan (musrif) termasuk dalam mengonsumsi makanan (Q.S.7:31; Q.S.4: 6). Allah mengancam tidak akan memberi petunjuk bagi orang yang melampaui batas (Q.S.40:28). Sikap melampaui batas termasuk salah satu faktor penyebab kesesatan (QS. 40:34). Allah tidak menyukai orang-orang yang melampaui batas (Q.S.6:41,7: 31). Salah satu penduduk neraka adalah orang yang melampaui batas (Q.S.40:43). Contoh pribadi yang melampaui batas dapat dilihat pada Fir'aun dan Qarun (QS.10: 73;44:31). Orang yang melampau batas akan dihancurkan Tuhan (Q.S.21:9), perintah agar tidak mematuhi orang yang melampaui batas (Q.S.26:151).

\section{Profil Singkat Muhammad Zuhri}

Muhammad Zuhri, guru Sufi yang berasal dari Sekarjalak di Pati, Jawa Tengah, Indonesia. Ia dikenal di lingkungannya dengan panggilan akrab Pak Muh, sembari menolak dengan panggilan kyai. Tidak seperti kebanyakan Sufisufi lain, dia tidak berasal dari tarekat manapun dan juga tidak berniat untuk mendirikan sebuah Tarekat baru (www.pakmuh.com, diakses, 13 Mei 2012).

Sebagian besar profil ini didasarkan pada blog www.pakmuh.com, dan diramu dari berbagai sumber. Dia lahir di Kudus, Jawa Tengah, pada bulan Desember 1939. Bersama orang tuanya dia pindah ke Pati. Lulus Sekolah Guru Bantu (SGB) dan menjadi guru SD (1957-1964). Di masa itu, dia bergabung Muhammadiyah dan turut aktif di dalamnya. Setelah mengundurkan diri sebagai guru $\mathrm{SD}$, mengembangkan mengembangkan bakatnya dalam seni lukis. Pilihan menjadi pelukis membuatnya merantau ke Semarang dan kemudian ke Jakarta. Di Jakarta, dia bertemu dengan seorang nenek sihir yang berusaha untuk membunuhnya. Akhirnya, sebuah doa yang berasal dari Sufi zaman silam mampu menolongnya mengalahkan penyihir tersebut. Pertemuan tersebut memberikannya pengalaman mistisnya yang pertama. Namun, perjalanannya menggeluti jalan sufi berlanjut terus, dan mengantarkannya ke beberapa guru sufi. Salah satu di antaranya adalah Kyai Hamid (Pasuruan), seorang kyai yang wali pada zamannya, yang melantik beliau menjadi seorang Guru Sufi.

Pak Muh menikah pada tahun 1961, dan dikaruniai dua putra, tiga putri (putri keempat meninggal dalam kecelakaan lalu lintas), ditambah sebelas cucu. Kini beliau hidup bahagia bersama keluarganya di desa Sekarjalak, Pati. Di rumah, dia membentuk halaqah kecil (forum diskusi tasawuf) yang diberi nama 
Pesantren Budaya Barzakh, yang mengadakan pengajian dua minggu sekali. Setiap bulan, dia juga mengunjungi murid-muridnya yang berada di Jakarta dan Bandung. Murid-muridnya yang di Jakarta mendirikan Yayasan Sosial Barzakh, sementara yang di Bandung membentuk Forum Kesenian Islam Keluarga Budaya Barzakh.

Konsep dasar tasawuf Pak Muh adalah sintesa dari kenabian Musa as dan Isa as yang berwujud kenabian Muhammad saw. Aktualisasinya berupa kreativitas yang positif ('amāl shālih) yang merupakan eksistensi manusia menurut ajaran Islam (lihat Surat Al Kahfi ayat 110 dalam al-Qur'an). Amal shalih di sini merupakan pertemuan antara makhluk dengan Sang Pencipta, maka di dalam amal salehnyalah letak 'transendensi spiritual' umat Islam (pengikut Nabi Muhammad SAW). Informasi lebih lanjut mengenai ajaran Pak Muh dapat diperoleh dari tulisan dan puisinya di berbagai buku dan media massa.

Banyak pendahulunya yang mempraktikkan penyucian diri dengan cara ekstrem, yaitu 'uzlah dan khalwat (Sufi Isa-is). Penyucian diri dilakukan dengan cara mengaktualisasikan diri dalam kehidupan lewat kreativitas yang dapat mengembangkan umat pada zamannya (Sufi Muhammad-is). Aktivitas keseharian di rumah mungilnya adalah menerima dan melayani tamu-tamu dari berbagai pelosok desa dan penjuru kota, yang datang untuk meminta nasehat atau pertolongan spiritual darinya untuk mengatasi berbagai masalah pribadi, keluarga atau sosial mereka. Selain itu, dia juga kerap menawarkan konsep berkehidupan berdasarkan pandangan Sufi.

Karya-karya dalam bentuk buku di antaranya adalah Qasidah Cinta (1993), Qasidah Cinta (Kumpulan Puisi Tasawwuf) (Bandung: Penerbit Pustaka, 1993), Langit-Langit Desa (Kumpulan Cerita Hikmat) (Bandung: Mizan, 1993). Artikel-artikelnya di beberapa harian dan majalah seperti: Tanggung Jawab Kreator, Secawan Anggur Cinta, Jalan Sufi di Zaman Globalisasi. Naskah ceramah di antaranya adalah, Peta Rububiyah, Paradigma Islam, Struktur Sholat, Puasa, Sikap Globalis yang Akurat, Selintas Menyingkap Rahasia Malam Qadar, Mencari Tuhan Lewat Seni?, Akhlaqul Karimah, Gaya Hidup Profetik, Sufi Healing, Misteri dan Makna Kematian, Sidratul Muntaha, Puasa Miniatur Perjalanan Kaum Muslimin, Sebuah Alternatif, Metodologi Proses, Menggapai Martabat Kholilullah, Rahasia Ismullahil-A'zhom-Nama Allah yang Keseratus. Sedang esainya di antaranya adalah Sajadah Merah Semangka. Adapun kisah Si Ubaid ditulis menjadi beberapa seri, yakni: Assalamu'alaikum Wr. Wb., Menjamah Lantai Kota, Restoran Metropolitan, Diri Kita yang Lain, Masih Ada Lowongan, Menunggu yang Haq, Berbahagialah Engkau, Sahabatku!, Sajadah Baru, Keledai atau Burung. Sementara itu, puisi-puisinya dapat dikelompokkan 
menjadi: Karya puisi tahun 1993 dan sebelumnya, Karya puisi tahun 1994, Karya puisi tahun 1995, Karya puisi saat Umroh (akhir 1995), Karya puisi tahun 1996, Karya puisi tahun 1997, Karya puisi tahun 1998, Puisi-puisi Millenium, Puisi Nyanyi Rajawali.

\section{E. Tradisi Lapar dan Pembentukan Etika Eco-Sufisme}

\section{Jalan Lapar: Transformasi Ruhani Insani ke Rabbani}

Menurut Zuhri, puasa adalah sebuah cara yang akurat di dalam mensikapi diri dan semesta (lingkungan/environment) agar dapat menjangkau kelestarian dan keseimbangan antara keduanya. Menurutnya, semua agama besar di dunia, baik agama samawi (wahyu) maupun agama wisdom (kebijakan) sepakat menggunakan puasa (mengurangi konsumsi makanan) sebagai satu-sat unya sarana teknis untuk mencapai kondisi diri yang bersitat rabbāni, yang mampu menawarkan keabadian. Ratusan juta umat manusia setiap tahunnya berusaha mempertahankan kelestarian diri dan semestanya dengan menempuh jalan lapar. (Zuhri, www.geocities.com, download, 29 Juni 2010).

Dalam konteks sejarah, memang belum ditemukan pencetus pertama kali yang melakukan ritus puasa (jalan lapar) ini. Bahkan tak seorang pun tahu siapa penemu "jalan lapar" yang keramat itu, walau demikian para nabi dan orangorang bijak di dunia tanpa ragu menghimbau umat manusia untuk menunaikannya. Secara normatif-dogmatis, al-Qur'an mengisyaratkan kepurbaan tradisi lapar tersebut lewat ayat: “... Kamā kutiba 'alalladzina min qalikum ..." (sebagaimana telah diwajibkan atas umat sebelum kamu’) (Q.S.2:183).

Secara sosio-antropologis, paling tidak ada dua hal penting dalam puasa, yakni 1) 'kesadaran akan kelangkaan sumberdaya alam' dan 2) 'kesadaran akan kebersamaan hidup'. Bila dua kesadaran tersebut bertemu di dalam diri seorang yang serakah (materialis), maka menurut pandangan Zuhri bahwa kedua sikap itu akan akan memunculkan sifat kolonialis dan imperialis.

Tetapi, ketika kesadaran tersebut bersemayam di dalam diri orang yang cinta akan kehidupan dan umat manusia, maka akan melahirkan sikap positif terhadap diri dan semestanya yang berwujud ibadah puasa, yaitu melatih ketahanan diri agar mampu memungut fasilitas alam seminimal mungkin untuk kebutuhan hidupnya. Karena fasilitas alam yang langka tak seharusnya diperebutkan dengan mengorbankan pihak lain atau dihamburkan untuk memanjakan nafsu, melainkan untuk dimanfaatkan seefisien mungkin demi kelestarian hidup bersama. Dengan demikian, ibadah puasa merupakan partisipasi orang beriman terhadap kemenijeran Tuhan di muka bumi. 
Selanjutnya, Zuhri mengatakan bahwa fenomena yang tampak pada pribadi yang ikhlas berkorban (șaimīn) demi kepentingan bersama adalah dimilikinya keteguhan hati di dalam menatap kenyataan dan pandangan yang positip terhadap kemungkinan. Dengan ungkapan lain, seorang yang puasa telah dikaruniai kondisi diri yang tidak cedera oleh perubahan ruang dan pergeseran waktu. Efek psikologis yang demikian itu wajar bagi seseorang yang telah berbuat sesuatu atau memberikan dirinya buat masa kini dan masa depan (Zuhri dalam pakmuh.com, diakses 29 Mei 2012).

Penghayatan puasa (yakni 'berkorban buat semua') selama satu bulan, menumbuhkan transformasi kesadaran yang berwujud lenyapnya "iradah insaniyah" menjadi "iradah rabbaniah", yaitu kehendak pribadi yang telah menjadi sesuai dengan kehendak Tuhan. Inilah pelajaran takhalluq bi akhlāq Allāh. Walau bermacam-macam kemampuan adi-kodrati dapat terungkap pula pada saat itu, namun Zuhri menegaskan bahwa itu bukan merupakan tujuan puasa yang Islami (Zuhri dalam pakmuh.com, diakses 29 Mei 2012).

Keberadaan seorang yang puasa lebih bersifat sebagai bonus dari Rabb al'ālamīn atau fadl Allāh bagi mereka yang menghendakinya (stimulan dari Allah). Tetapi stimulan bisa berdampak negatif bagi orang yang cukup puas dengan fasilitas tersebut dan tidak tergerak untuk mencapai tujuan puasa yang sebenarnya.

\section{Jalan Lapar: Jalur Cepat/Quantum Transformasi Ruhani}

Bagi Zuhri, puasa adalah sebuah ibadah yang bersifat temporal dan berorientasi pada kebenaran. Itu sebabnya, puasa belum tentu dapat membuahkan sebagaimana yang dijanjikan -yaitu taqwa, sebelum pelakunya memiliki tujuan yang benar terlebih dahulu. Tujuan puasa adalah mengabdi kepada Allah demi mencapai ridha-Nya, yang dinyatakan lewat perbuatan shalat (Zuhri dalam www.geocities.com download 22 Juni 20012). Dalam konteks ini, Zuhri mencoba mengaitkan antara puasa dengan shalat sebagai satu kesatuan yang utuh.

Menuju Tuhan adalah perjalanan yang amat jauh dan berliku. Bagi Zuhri, perjalanan ke sana adalah perjalanan yang teramat jauh untuk dapat dijajaki dengan ukuran ruang dan waktu. Dengan demikian, jika dikaitkan dengan usia manusia, maka usia manusia terlalu pendek untuk meraihnya. Oleh karena pendeknya usia itu, maka diperlukan waktu yang efisien, yang memungkinkan seseorang untuk melakukan lompatan-lompatan (quantum). Cara quantum atau lompatan tersebut pada dasarnya adalah transendensi-transendensi yang tidak berdampak melumpuhkan kemandirian manusia sebagai makhluk individu. Maksudnya, manusia masih tetap potensial menanggungjawab eksistensinya 
di muka bumi, sehingga urusan duniawinya tidak bergant ung kepada pihak lain. Selain itu, dapat berlangsung di dalamnya proses transformasi kesadaran terhadap makna 'diri' dan 'semesta'-nya.

\section{a. Self and Cosmic Conciousness}

Bagi Zuhri, seseorang tidak akan dapat menyadari nilai apa pun di dunia ini sebelum ia bersedia mengambil jarak darinya dan menjadikannya sebagai objek pemahaman. Dengan kata lain, jika sesuatu itu masih berada pada kediriannya maka pemahaman tersebut akan bias bahkan salah. Demikian pula bila seseorang ingin mengenal 'diri' sekaligus medan operasionalnya yang berupa 'alam', kita harus rela berjarak dengan-nya. Caranya dengan melaksanakan ibadah puasa, yaitu berhenti melayani tuntutan-tuntutan 'jiwa' dan 'raga' selama waktu tertentu. Pada saat itu, seseorang akan merasakan betapa lemahnya 'diri' dan betapa tingginya nilai sumber daya alam (rahmat) bagi kehidupan manusia (Zuhri, pakmuh.com, diakses, 16 Juni 2012).

Dengan kata lain, puasa adalah upaya membuat jarak antara diri dengan tuntutan diri. Jarak ini kemudian dapat memberikan peluang bagi pelakunya untuk menemukan makna di balik peristiwa. Dalam konteks Ibn 'Arabī, peristiwa (ibadah) tersebut adalah teofani Tuhan. Jarak yang diciptakan secara sengaja menjadi proses pembelajaran berkaitan dengan makna kehidupan.

Lebih lanjut Zuhri mengatakan bahwa, sebelum itu seringkali manusia memiliki praduga yang salah terhadap kenyataan. Sebagai manusia, seringkali selalu merasa lebih tinggi dibanding makhluk lain yang ada di kolong langit. Alam dan seluruh isinya, bagi kita yang manusia seisinya dianggap sebagai milik yang sepantasnya untuk dinikmati sepuas-puasnya, diperebutkan, dan dimanfaatkan sekehendak hati. Seolah dunia ini boleh saja kiamat setelah digunakannya. Padahal tidak demikian kenyataannya.

Kerusakan alam, sebagaimana yang tampak berawal dari keserakahan manusia, yang boleh jadi karena pemahaman yang keliru memandang alam. Pemahaman yang keliru tersebut bisa jadi salah interpretasi dari ajaran kitab suci yang di dalamnya memang mengatakan bahwa alam disediakan untuk manusia. Walaupun demikian, masih terdapat ayat lain yang dapat dipahami bahwa alam adalah sahabat manusia yang keberadaannya adalah bersama manusia. Pemahaman yang keliru bahwa manusia lebih hebat dibanding alam semesta dikoreksi Tuhan sebagai berikut: "Sungguh, penciptaan langit dan bumi jauh lebih hebat dari penciptaan manusia. Sayang, kebanyakan manusia tidak mengetahui" (Q.S.31: 57; Q.S.95:5).

Menurut Zuhri, ketinggian martabat manusia di depan alam bukanlah terletak pada 'persepsi mereka' tentangnya, melainkan pada 'irādah' Tuhan yang 
menjadikannya sebagai khalifah di muka bumi (Q.S.2:30,34).

Pada bagian lain, Zuhri juga menjelaskan bahwa sebelum manusia menemukan dirinya sebagai makhluk sejarah yang dapat "berjalan" menembus kemungkinan-kemungkinan, manusia adalah makhluk kosmis yang beredar dalam pengulangan pengulangan yang tak terhindarkan, antara diam dan bergerak, tidur dan jaga, pergi dan pulang, tumbuh dan berkembang biak, hidup dan mati dan sebagainya. Dengan kata lain, manusia seperti makhluk pada umumnya (Zuhri, pakmuh.com, diakses, 16 Juni 2012).

Dalam konteks ini manusia harus berjuang menembus kemungkinankemungkinan yang diduga dapat menyampaikannya pada situasi bebas dan abadi. Namun tidak demikian kenyatannya. Kemungkinan-kemungkinan yang diambilnya tidak selalu menyampaikan mereka kepada yang diharapkan, bahkan sering- sebaliknya. Hal itu disebabkan kemungkinan yang diungkapkannya belumlah merupakan kemungkinan yang terbaik buat dirinya. Dalam konteks ini, menempuh kemungkinan yang terbaik adalah melaksanakan amr Allah, yang dijamin oleh hukum qudrat serta irādah (Zuhri, pakmuh.com, diakses, 16 Juni 2012).

Kebesaran jiwa seseorang tidak dapat diukur dengan kekuatan fisik dan intelegensinya, melainkan dengan tanggungjawabnya terhadap nasib umat. Dan kebesaran tanggungjawabnya terhadap umat tergantung kepada rasa cintanya terhadap sesama. Adapun rasa cintanya terhadap sesama tidak mungkin bisa tumbuh tanpa adanya citra ke-Tuhan-an di dalam diri. Hal itulah yang membuat Nabi Ibrahim siap mengorbankan segala-segalanya, sejak dari milik hingga seutuh waktu hidupnya demi keselamatan umat manusia dari kiblat hidup yang nyasar. Sikap hidup kaum muslimin tidak bergant ung pada 'persepsi' yang selalu berubah-ubah sifatnya dan tidak keruan ujungnya. Selain itu, persepsi hanyalah hasil aktivitas akal di dalam menginterpretasikan fenomena alam (kehidupan) untuk mengembangkan wawasannya tentang kenyataan, dan tidak akan pernah memadai untuk diangkat sebagai pemandu kehidupan.

Zuhri menegaskan bahwa biang keladi kejatuhan iblis dari surga ke dalam neraka adalah karena ia mencoba menggunakan 'persepsi'-nya untuk membantah Tuhan, ketika ia disuruh bersujud kepada Adam. Sabda Tuhan: 'Apa yang menghalangimu untuk bersujud ketika $\mathrm{Ku}$ perintahkan kepadamu?' Iblis menjawab (berpersepsi): 'Aku lebih mulia darinya. Kau ciptakan aku dari api, sedang ia Kau ciptakan dari tanah liat." (QS.7:12).

Potensi yang dimiliki manusia berupa akal yang diamanatkan Allah untuk mengurus alam, namun justru disalahgunakannya untuk kepentingan pribadi 
(nafsu, etnis, ideologi). Akibatnya, mereka akan menemukan dirinya sebagai budak benda-benda dan ciptaannya sendiri.

b. Situasi Komunikatif dengan Tuhan

Pemikiran lain yang berkaitan dengan jalan lapar, Tuhan, dan alam disebut Pak Muh dalam konsepsi tentang transendensi. Transendensi yang terjadi pada saat seseorang berjarak dengan 'diri' dan 'alam'-nya adalah di saat mereka dapat berada dalam 'situasi komunikatif' dengan Tuhannya. Dengan kata lain, seseorang telah memiliki kondisi layak berdialog dengan Allah (Zuhri, pakmuh.com, diakses, 16 Juni 2012).

Sebagai figur khalifah, setiap insan memiliki kepentingan yang sangat besar untuk dapat berdialog dengan Majikannya, supaya ia tahu persis apa maunya 'Sang Majikan' dengan menurunkan berbagai macam kenyataan seperti baik-buruk, salah-benar, suka-duka dan sebagainya. Dengan demikian perjalanan hidupnya tidak hanya akan diwarnai dengan ketegangan, kesedihan atau keputusasaan yang tak pernah purna.

Menurut Zuhri, tokoh Nabi Musa AS yang hidup di perantauan dan di bawah kekuasaan Fir'aun yang perkasa dan zalim merupakan lambang penderitaan seorang musafir di bumi Tuhan. Ketika pengembaraannya sampai di bukit Sinai, beliau diperintah Tuhan untuk menanggalkan kedua terompahnya, supaya dapat diajak berdialog demi mencairkan stagnasinya. Dalam konteks ini, Zuhri menggunakan rujukan quranik yakni QS.20:12.

Dua terompah 'kanan dan kiri' merupakan simbol dari kedua pijakan manusia di atas semesta eksistensial, yaitu jiwa dan raganya. Allah tidak berkenan berkomunikasi dengan hamba-Nya, selama baju eksistensialnya (jiwa dan raga) belum dilepaskan.

Demikian pula halnya dengan kaum Muslimin di bulan Ramadan. Sebelum berbuka puasa permohonan mereka akan diterima Tuhan (komunikatif dengan Tuhan). Tentu saja bukan permohonan yang akan merusak situasinya pada saat itu, melainkan tentang apa saja yang diperlukannya di dalam rangka menyelamatkan umat dan semestanya, termasuk kebutuhan pribadinya sebagai khalifah. Mereka memohon ridla Allah untuk mengungkapkan segala bentuk potensi diri dan alamnya. Pak Muh menggunakan rujukan doa yang berasal dari hadits nabi, yang artinya:

"Ya Allah, kami memohon ridla-Mu dan efektivitasnya (surga), dan kami berlindung dari murka-Mu dan akibatnya (neraka)."Ya Allah, Engkaulah Yang Maha Pengampun dan suka memberi ampunan. Ampunilah kami, wahai Yang Maha Dermawan." 
Jalan lapar, termasuk di dalamnya berpuasa adalah menciptakan lebih banyak peluang untuk dapat berkomunikasi dengan Tuhan, merenungkan keberadaan alam semesta, serta menghemat sumber daya alam.

c. Menemukan Diri Sebagai Raja

Kondisi șāimīn (orang yang puasa) pada saat melepaskan diri dari pengaruh jiwa dan raganya adalah 'kondisi kematian'. Ketika itu martabat spiritual mereka setara dengan martabat spiritual seorang Raja yang adil atau seorang hamba yang teraniaya/ madzlūm (Tiga golongan yang doanya dikabulkan Tuhan - Hadits Nabi SAW) (Anomim, T.T: 532).

Bagi Zuhri, penderitaan mereka mengisyaratkan wujudnya kekuatan dahsyat yang tersembunyi di balik dirinya. Mereka tidak memungut fasilitas alam untuk menopang tubuhnya, tetapi dihimbau untuk mengeluarkan shadaqah yang sebanyak-banyaknya. Mereka adalah sekelopok orang yang tidak sanggup menyembunyikan sesuatu di tengah-tengah masyarakatnya yang kekurangan. Bahkan mereka lebih mengutamakan kepentingan pihak lain meskipun diri mereka sendiri sangat membutuhkan (lihat Q.S.59:9).

Săimin rela menunda segala kenikmatan yang dapat mereka pungut kapan saja mereka mau, _ bukan untuk apa-apa, hanya mau mengajari diri sendiri unt uk bersabar, karena nikmat yang diharapkannya hanya ada di hari liqa (berjumpa Allah). Itu penderitaan pun tidak menjadi tampak penting di matanya, karena yang mereka risaukan hanya liqā yang dirisaukan hanyalah ridha Tuhan.

"Waj'al khaira ayyami yauma alqaka fihi” 'Dan jadikanlah sebaik-baik hariku, hari pertemuanku dengan-Mu'.

Pejalan penempuh lapar adalah orang yang telah berhasil menegakkan pengawas, hakim, dan bahkan raja - paling tidak buat diri mereka sendiri. Lebih dari semua itu, — tetapi hal ini mungkin tidak mereka sadari, telah tumbuh di dalam sanubari mereka rasa cinta-kasih yang besar terhadap seluruh kehidupan yang terhampar di cakrawala ini. Dan itu berarti bahwa mereka telah memetik kebahagiaan yang berlimpah, utuh, dan abadi dari kehidupan mereka (lihat Q.S. 55: 26).

Selanjutnya Zuhri mengatakan bahwa keberanian mereka menghayati kematian seperti itu sama artinya dengan keberanian menanggalkan kepribadiannya yang lama. 'Keberanian menanggalkan kepribadian yang lama' merupakan bagian integral dari proses perkembangan mental dan spiritual umat manusia. Hidup, mati, kemudian hidup kembali dengan sikap yang baru- dan seterusnya, adalah 'irama kreativitas Tuhan' yang dawam di dalam mengem- 
bangkan makhluk-Nya ('Idul Fitri). Ini selaras dengan sabda Nabi yang mengatakan bahwa, 'Tiada berkah matahari terbit hari ini - bagiku, bila diriku tidak lebih baik dari kemarin.

Kekuatan dahsyat di dalam menghayati penderitaan tanpa mengeluh yang tersembunyi di dalam diri șāimīn, membuat mereka terpanggil untuk melayani semestanya. Dan rasa cinta-kasih yang bersemayam di dalam dadanya membuat mereka siap untuk memenuhi panggilan tersebut (lihat Q.S.28:77).

Demikianlah semestinya kualitas 'Ṣibghah (celupan) Tuhan' - yang jauh berbeda dengan sentuhan alam (lihat Q.S.2: 138). Mereka selalu siap memberikan apa saja yang dimilikinya kepada siapa yang membut uhkan (lihat Q.S.5:3,3:92), meski tak seorang pun pernah dapat menolongnya (lihat Q.S.53:39). Karena apa yang mereka butuhkan tak dapat diberikan oleh siapa pun selain Allah, yaitu 'ridla-Nya' (lihat Q.S.5:119).

Momen transendensi dari seorang budak hawa nafsu menjadi seorang raja yang mampu mengantarkannya ke haribaan Allah itulah yang dinamakan saat Lailatul Qadar (lihat Q.S. 97: 3). Itulah hari kebangkitan jiwa dari kuburan tubuh (qiyāmat sughrā), dan itu pula yang disebut sebagai 'saat' yang ditunggu-tunggu oleh seluruh warga alam, karena kehadirannya akan membawa perubahan besar di dalam semestanya (Q.S.5: 54).

\section{F. Simpulan}

Tradisi lapar adalah media unt uk pengenalan diri (self recognition). Jika seseorang telah dapat mengenal diri, maka secara bertahap akan mengetahui kualitas diri. Manusia, secara individual adalah diri yang lemah. Diri ini tidak bisa hidup tanpa bantuan aspek lain, yaitu manusia lain dan alam semesta.

Berangkat dari pengenalan akan kesadaran diri ini kemudian bertransfomasi pada kesadaran kosmis. Alam harus dirawat dijaga, dan dilestarikan. Dalam konteks ini kosmos dan diri adalah "teofani" Tuhan. Manusia adalah sebagai khalifah yang mengabdi pada Tuhan dan sekaligus merawat alam semesta. Puasa dalam agama-agama mengajari kesadaran ini. Puasa sebagai salah satu tradisi sufi memiliki fungsi multi, yakni sebagai wașīlah agar seseorang dapat dekat dengan Tuhan, manusia, dan alam semesta. Puasa dalam Islam adalah tradisi yang sangat pro terhadap lingkungan. Secara ekologis, puasa adalah bentuk dari kegiatan reducing consumption dan melatih diri agar jauh dari ketamakan duniawi. 


\section{Daftar Pustaka}

A. Buku dan Jurnal

al-Ghazā̄i. TT. Ihyā' Ulūm al-Dīn, Juz IV. TTP: Maktabah Dār Ihyā' al-Kutub al-'Arabiyyah.

Al-Qusyairī. TT. al-Risālah al-Qusyairiyyah fī 'Ilm Tashawwuf. TTP: alMaktabah al-Taufiqiyyah.

Azra, Azyumardi (Ed.). 2008. Ensiklopedi Tasawuf, Jilid III. Jakarta: UIN Syarif Hidayatullah

Baldick, Julian. 1986. Mystical Islam; An Introduction to Sufism. New York: New York University Press.

Cassidy, V. M. 2007. Henry Chandler Cowles - Pioneer Ecologist. Chicago: Kedzie Sigel Press.

Coleman, W. 1986. "Evolution into Ecology? The Strategy of Warming's Ecological Plant Geography" dalam Journal of the History of Biology, 19 (2), 1986.

Coward, Harold. 1993. "Religious Responsibility". In Ethics \& Climate Change: The Greenhouse Effect, dalam Harold Coward \& Thomas Hurka (Eds.). Canada: Wilfrid Laurier University Press.

Dalai Lama and Jean-Claude Carriere. 1994. Violence \& Compassion. New York: Doubleday, Bantam Doubleday Dell Publishing Group, Inc.

Djamil, Abdul. 2001. Perlawanan Kyai Desa. Yogyakarta: LKiS.

Durning, Alan Thein. 1994. "The Conundrum of Consumption." Dalam Laurie Ann Mazur (Ed.), Beyond the Numbers: A Reader on Population, Consumption, and the Environment. Washington, D.C./Covelo, California: Island Press.

Eliade, Mircea. 1987. The Encyclopedia of Religion. New York: Macmillan Publishing Company.

Ersnt, Carl W. 2003. Ajaran dan Amalan Tasawuf. Yogyakarta: Pustaka Sufi. Harrison, Peter. "Subduing the Earth: Genesis 1, Early Modern Science, and the Exploitation of Nature", The Journal of Religion, 79 (1), hal. 86-88. Hayden, Tom. 1996. The Lost Gospel of the Earth: A Call for Renewing Nature, Spirit \& Politics. San Francisco: Sierra Club Books.

Horner, I.B. 1959. "Buddhism: The Theravada" dalam R.C. Zaehner (Ed.), The Concise Encyclopedia of Living Faith. London: Hutchinson.

Huda, Sokhi. 2008. Tasawuf Kultural, Fenomena Shalawat Wakhidiyah. Yogyakarta: LKiS. 
Ikeda, Daisaku. Dialogue on Life: Buddhist Perspectives on Life and the Universe. Tokyo: Nichiren Shoshu International Centre.

Kartodirdjo, Sartono. 1970. Religious Movement in Java in the $19^{\text {th }}$ and $20^{\text {th }}$

Century. Yogyakarta: Gadjah Mada University Press.

Kolandai, Komathi. 1999. A Spiritual Appeal To Environmental Behaviour: Addressing Global Problems Of Population Growth And Consumption.

Lund: Lund University Sweden.

Northcott, Michael, S. 1996. The Environment \& Christian Ethics. New York: Cambridge University Press.

Rayan, Samuel, 1999. "Theological Perspectives on the Environmental Crisis". Religion and Society, Vol. XXXVII (2): 18-34., hal. 19.

Renard, John. 1999. Responses to 101 Questions on Hinduism. New York: Paulist Press.

Schimmel, Annemarie. 1992. A Two-colored Brocade: The Imagery of Persian Poetry. Chapel Hill: University of North California Press.

Sirriyeh, Elizabeth. 1999. Sufis dan Anti-Sufis. England: Curzon Press. 2003. Sufis and Anti-Sufis; The Defence, Rethinking and

Rejection of Sufism in the Modern World. London: RoutledgeCurzon.

Suryadi. 2001. "Shaikh Daud of Sunur: Conflict between Reformists and Shattariyyah Sufí Order in Rantau Pariaman in the First Half of the Nineteenth Century," dalam Studia Islamika. Vol. 8, No. 3. hal. 57-124. Suwito NS. 2004. Transformasi Sosial; Epistemologi Pemikiran Islam Modern Ali Syari'ati. Purwokerto-Yogyakarta: STAIN Purwokerto Press dan Unggun Religi.

Syirbashī, Aḥmad. TT. al-Ghazālì wa Tashawwuf al-Islāmy. Beirut: Dār alHilāl.

Toynbee, A. 1972. "The Religious background to the Present Environmental Crisis”, International Journal of Environmental Studies, 3: 141-146. hal. 141.

White, Lynn. 1967. "The Historical Roots of Our Ecologic Crisis", Science 155 (3767): 203-1207.

Woodrum, Eric and Beth L. Davison. 1996. "Images of God and Environmentalism", Research in The Social Scientific Study of Religion, 7, hal. 77.

Zuhri, Muhammad Menggapai Martabat Khalifatullah (Makalah) Disampaiakan pada Acara Seminar Studi Tasawuf oleh Yayasan Barzakh di Balai Diklat Depkes Jakarta, pada tanggal 18 Maret 2001. 
B. Internet

http://bambangsb.blogspot.com/2006/05/masjid-menara-kuduskesinambungan. html (Didownload pada 17 Maret 2007).

http://books.google.co.id/books?id=1 oLCW1Yn5eIC\&pg=PA75\&lp $\mathrm{g}=\mathrm{PA} 75 \& \mathrm{dq}=\% 22$ konsumsi + dalah $\% 22 \&$ source $=$ bl\&ots $=\mathrm{QhP}$ esWdxDH \&sig=nZiWa3NHO 20gjIyReVy12Esw8Z8\&hl=id\&ei=6dxBSpeDBJ Xo7AP1tfmMCQ\&sa=X\&oi=book_result\&ct=result\&resnum=2 (Download, 24 Juni 2009).

http://en.wikipedia.org/wiki/Gilles_Deleuze (Didownload pada 3 April 2009). http://id.wikipedia.org/wiki/ReinkarnašiReinkarnasi_dalam_Hinduisme (Download, 24 Juni 2009).

http://www. en.wikipedia.org/wiki/Sufi_Order_International. Lihat juga http:/ /www.om-guru.com/html/saints/khan. html (Download, 11 Maret 2009). http://www.geocities.com/Athens/5739/muhzuh-i.htm (Download, 24 Juni 2009).

Machasin, Luthfi. 2006. "Islamisasi dan Masyarakat Pasar: Sufisme dan Sejarah Sosial Kota Sokaraja" dalam http://lafadl.wordpress.com/2006/09/15/ islamisasi-dan-masyarakat-pasar-sufisme-dan-sejarah-sosial-kotasokaraja/

Zuhri, Muhammad. "Puasa, Sikap Globalis yang Akurat”, dalam http:// www.geocities.com/Athens/ 5739/muhzuh-i.htm (Download, 24 Juni 2009).

Zuhri, Muhammad. Puasa Miniatur Perjalanan Muslim dalam ttp:// www.geocities.com/Athens/ 5739/muhzuh-i.htm (Download 22 Juni 2009).

C. Majalah dan Surat Kabar

Panji Masyarakat No. 786 (21-31 Maret 1994).

Amanah, No. 209 (22Juli-4 Agustus 1994).

Majalah TEMPO edisi 29 Januari 1994.

Harian Terbit, Edisi Sabtu, 10 Februari 1996.

Panji Masyarakat, No.17 Tahun III (11 Agustus 1999).

Harian Terbit, Edisi Sabtu, 10 Februari 1996.

Panji Masyarakat, No. 17 Tahun III (11 Agustus 1999).

Amanah, No. 209 (22Juli-4 Agustus 1994).

Majalah Panji Masyarakat, No. 786 (21-31 Maret 1994).

Surabaya Pos, Edisi Minggu, 30 September 1990. 
Surabaya Pos edisi Minggu, 30 September 1990.

Suara Merdeka, Edisi Minggu, 28 November 1993.

Suara Merdeka, Edisi Minggu, 28 November 1993.

Majalah TEMPO edisi 29 Januari 1994.

Panji Masyarakat, No. 32 Tahun I (24 November 1997).

Majalah Panji Masyarakat, No. 32 Tahun I (24 November 1997).

Tabloid Senior, No. 09 (27 Agustus - 2 September 1999).

Tabloid Senior, No. 09 (27 Agustus - 2 September 1999).

Majalah Panji Masyarakat, No. 778 (1-10 Januari 1994).

Panji Masyarakat No. 778 (1-10 Januari 1994). 